\title{
REPRESENTAÇÃO DA REALIDADE EM “O PINTOR DE RETRATOS” E “A MARGEM IMÓVEL DO RIO”, DE LUIZ ANTONIO DE ASSIS BRASIL
}

\section{Fabio Augusto Steyer*}

\begin{abstract}
Resumo: O objetivo deste trabalho é analisar dois livros do escritor gaúcho Luiz Antonio de Assis Brasil cujo objetivo principal é discutir a representação da realidade em diferentes linguagens. "O Pintor de Retratos" (2001) trata do debate entre fotografia e pintura como instrumentos de captação "objetiva" da realidade, a partir de um enredo que se passa no final do século XIX. Em "A Margem Imóvel do Rio" (2004) o problema da representação da realidade volta-se para a Literatura e a História. Também ambientado no final do século $X I X$, narra a história do cronista oficial da corte de D. Pedro II, que viaja ao Rio Grande do Sul em busca de Francisco da Silva, a quem o imperador teria prometido um título nobiliárquico. Além das temáticas de cada livro, a idéia deste estudo é discutir também as próprias obras literárias do autor como produtoras de sentido(s) para a construção de uma determinada visão sobre a representação das realidades abordadas.
\end{abstract}

Palavras-chave: Literatura. Representação. Realidade.

\begin{abstract}
"Ninguém quer ser retratado como é, mas como gostaria de ser. De qualquer forma, [...] no futuro a real feição do homem passava a ser a do retrato".

Luiz Antonio de Assis Brasil, em "O Pintor de Retratos".

"Depois, em dois ou três movimentos da borracha sobre o papel, o Historiador apagou o nome que o martirizara. Francisco da Silva desaparecia da memória, tragado nas paragens do Sul. E a História passava a ser outra".
\end{abstract}

Luiz Antonio de Assis Brasil, em “A Margem Imóvel do Rio”.

Este texto trata de dois romances publicados no início do século XXI, mas de largada nos remete a um debate muito caro à literatura e às mais diversas linguagens e formas narrativas em qualquer época que se queira analisar: a questão da representação da realidade. Isso tudo talvez tenha começado com Aristóteles e a sua "Poética", na remota Antigüidade Clássica, e até hoje nunca se deixou de discutir o assunto.

Para falar apenas da literatura brasileira e de um momento específico em que o tema foi amplamente discutido, façamos referência à segunda metade do século XIX e à virada deste para o século XX. O período, aliás, é tema de "O Pintor de Retratos", que analisaremos a seguir, e não deixa de ser interessante pensarmos em algumas questões de cem anos atrás quando nossos objetos de estudo fazem parte da virada seguinte, a do século XX para o XXI.

Mas o momento a que gostaríamos de nos referir é o do Realismo/Naturalismo, com todo o embate contra os valores românticos e a tentativa de se escrever uma literatura de

\footnotetext{
* Doutor em Letras pela Universidade Federal do Rio Grande do Sul. Professor adjunto da Universidade Estadual de Ponta Grossa. E-mail: fsteyer@uol.com.br.
} 
caráter (supostamente) objetivo e quase "científica". O que nos interessa sublinhar é que, a par desta visão da escola realista/naturalista, em que a representação da realidade assumia essa intenção de "verdade", de "representação o mais fiel possível", um dos nossos maiores escritores, Machado de Assis, construía uma postura extremamente crítica e muito mais alinhada à virada do nosso tempo, a do século XX para o XXI - e mais alinhada também àquilo que Assis Brasil descreve em suas obras.

Isso fica claro quando Machado critica Eça de Queirós e seus excessos (no seu famoso ensaio sobre "O Primo Basílio"), ou ainda quando aponta as falhas daquilo que denomina "instinto de nacionalidade" (no ensaio de mesmo nome, um de seus principais textos $\operatorname{críticos}^{1}$ ). Para ele, não bastava romper com os valores românticos e tratar do "nacional" de forma "objetiva e realista". Era preciso um equilíbrio entre tradição e originalidade, além de que é a qualidade do autor que o faria escrever boa literatura, e não o simples fato de dissertar sobre temas brasileiros.

\title{
Como afirma Marta de Senna:
}

\begin{abstract}
"Notícia da literatura brasileira: instinto de nacionalidade" é uma defesa da ideia de que o bom escritor é, sobretudo, o escritor de talento, e não o escritor que faz do nacionalismo uma bandeira, ou aquele que se limita a cantar as coisas típicas ou exclusivas de sua terra. Dirá, em frase que parece antecipar uma das mais reincidentes (e míopes) críticas que sua própria obra haveria de receber: '[...] manifesta-se às vezes uma opinião que tenho por errônea: é a que só reconhece espírito nacional nas obras que tratam de assunto local' (p. 803). E exemplifica, irrefutavelmente, com Gonçalves Dias, argumentando que, se valesse o critério da "brasilidade", só se apreciaria a obra nativista, deixar-se-ia de fora a belíssima poesia lírica do maranhense, cujos versos "pertencem [...] pelo assunto, a toda a mais humanidade, cujas aspirações, entusiasmo, fraquezas e dores geralmente cantam” (2009, p. 77-78).
\end{abstract}

O debate proposto por Machado de Assis é complexo, colocando em xeque a própria classificação que até hoje é feita para sua obra em nossos livros didáticos: a fase romântica e a fase realista. "Enquadrar" sua obra nestas fases se torna complicado, pois o próprio autor procurava, na época, superar esta classificação. Além disso, seu "realismo" não é o da "representação fiel da realidade". Talvez seja o da "complexidade da realidade". Seus narradores não são "objetivos e verdadeiros", mas, sim, "oblíquos e dissimulados". O mesmo se pode falar de muitas de suas personagens, tanto nos contos como nos romances, além das situações inconclusas, em aberto, propícias a uma pluralidade de interpretações pela parte dos leitores. Não fosse assim os alunos de ensino médio não debateriam até hoje a questão da traição de Capitu!

Aliás, nesta realidade múltipla, complexa, oblíqua, enfim, plural, não há um "quê" da nossa contemporaneidade, ou seja, a da virada do século XX para o XXI? Daquela época que uns denominam pós-modernidade e outros, como Arlindo Machado ${ }^{2}$, preferem chamar de "contemporaneidade" ou "neobarroco"?

\footnotetext{
${ }^{1}$ Ambos os textos estão referenciados no final deste trabalho.

${ }^{2}$ Refiro-me aqui a diversos textos publicados na coletânea: MACHADO, Arlindo. Pré-Cinemas e póscinemas. Campinas: Papirus, 1997. Em especial, aquele intitulado "Formas expressivas da contemporaneidade" (p. 236-249).
} 
Pois é lembrando Machado que gostaríamos de começar a falar dos romances que são objeto deste texto.

"O Pintor de Retratos" (2001) e "A Margem Imóvel do Rio" (2003), romances do escritor gaúcho Luiz Antonio de Assis Brasil, são considerados pelo próprio autor como integrantes de um "díptico" que ele batizou de "Visitantes ao Sul", obras que revelariam um "olhar estrangeiro sobre o pampa" 3 . São livros que marcam uma nova fase na obra de Assis Brasil, que passa do texto um tanto barroco de seus romances anteriores, especialmente "Breviário das Terras do Brasil", para o uso de uma linguagem mais enxuta, direta, objetiva, embora no que se refere à temática muitos aspectos em comum ainda estejam presentes.

Importante dizer que são duas obras bastante significativas se considerarmos a produção recente de romances brasileiros, especialmente na vertente do romance histórico. E que receberam prêmios importantes: "O Pintor de Retratos" foi agraciado com o Prêmio Machado de Assis, da Biblioteca Nacional (2001); e "A Margem Imóvel do Rio" foi um dos três vencedores do Prêmio Portugal Telecom de Literatura Brasileira (2004), além de ser um dos três indicados ao Prêmio Jabuti (2003), na categoria Romance.

As referências a momentos importantes da história do Rio Grande do Sul sempre foram temáticas recorrentes na obra de Assis Brasil. Com os dois livros citados acima não poderia deixar de ser diferente. Ambos retratam aspectos da história da capital e do interior do Estado na segunda metade do século XIX, época de grandes transformações sociais, políticas, econômicas e culturais. A República, a abolição da escravatura, a Guerra do Paraguai, a Revolução Federalista, o surgimento do cinema e o realismo, na literatura, fotografia e artes plásticas, são algumas características marcantes deste período de intensa agitação social.

Nos dois livros de Assis Brasil há inúmeras referências à realidade gaúcha da época, sendo que a forma de representar essa realidade é que nos parece ser passível de análise. Em primeiro lugar, cabe um comentário sobre o estilo de Assis Brasil ao escrever cada uma das obras. Em "O Pintor de Retratos" a linguagem é extremamente enxuta, sendo que há uma enormidade de referências a nomes, locais, enfim, dados através dos quais o autor pretende ambientar historicamente a narrativa. Pode-se dizer inclusive que para um texto tão enxuto há até um excesso de referências históricas, o que prejudica a representação da realidade, provocando no leitor, às vezes, ao invés de uma sensação de "realismo", uma idéia de "artificialismo". A linguagem de "A Margem Imóvel do Rio" também é enxuta, mas não tanto, e as referências históricas, embora também apareçam em grande quantidade, são em menor número do que na obra anterior. Há, portanto, no segundo livro, um maior equilíbrio entre a utilização da linguagem e o uso das referências históricas, o que, a nosso ver, contribui para a concretização de um texto mais realista e formal, tematicamente falando, que é mais eficiente na aproximação do leitor à realidade que está sendo retratada.

Em "O Pintor de Retratos", o abuso na utilização de referências à realidade acaba por provocar um certo tom de irrealidade nas descrições feitas pelo narrador. É o que ocorre, por exemplo, nas diversas passagens em que as personagens desfilam pela

\footnotetext{
${ }^{3}$ Segundo nota de Luiz Antonio de Assis Brasil, no final de "A Margem Imóvel do Rio".
} 
geografia da capital gaúcha ou mesmo do interior. Desta forma, Sandro Lanari, personagem principal do livro, almoça no Ao Cornudo Galante ou no Restaurant Bom Gosto, cruza o Theatro São Pedro ou a Praça da Alfândega, viaja de barco pelo Jacuí, "o de margens imprecisas" (p. 101), observa um relógio Regulator, lê notícias no Correio do Povo e recebe balanços financeiros do Banco da Província, entre várias outras coisas. $\mathrm{O}$ problema é que todas essas referências parecem um tanto forçadas, ou seja, o fato de serem citadas nominalmente é que fornece ao leitor a idéia de sua existência real. Se ao invés de Rua da Praia estivesse escrito Rua Dr. Flores a descrição seria a mesma. Isso significa que a descrição geográfica/espacial dos locais ou a descrição precisa dos objetos retratados é substituída por meras citações nominais, que poderiam ser trocadas por quaisquer outras, sem alteração de sentido. Ou seja: a Rua da Praia só é Rua da Praia porque está citada nominalmente no livro, e não porque possui determinadas características que a tornam singular. Este tipo de referencial, portanto, acaba por tornar artificial e forçada a tentativa de representar aspectos da realidade gaúcha do final do século XIX, como se isso fosse possível apenas através de citações a fatos, nomes, objetos, pessoas, etc ${ }^{4}$.

Embora os contextos sejam totalmente diferentes e a comparação talvez inapropriada, lembro aqui novamente de Machado de Assis, que em seu famoso texto sobre "O Primo Basílio" criticava os "excessos" da escola realista:

\footnotetext{
Não peço, decerto, os estafados retratos do Romantismo decadente; pelo contrário, alguma coisa há no Realismo que pode ser colhido, em proveito da imaginação e da arte. Mas sair de um excesso para cair em outro, não é regenerar nada; é trocar o agente da corrupção.

[...] Voltemos os olhos para a realidade, mas excluamos o Realismo, assim não sacrificaremos a verdade estética (ASSIS, 1962, p. 910).
}

A questão aqui remete mesmo ao Realismo/naturalismo e seus excessos, que, lembrando Aristóteles, parece querer se aproximar mais da História (ou da noção de "verdade") do que da Literatura (ficção), ou seja, mais daquilo "que propriamente aconteceu" do que daquilo que seria "possível" ou "plausível” de acontecer. É claro que, assim como acontece com o cinema, a pintura e com a fotografia, essa separação entre História e ficção se torna extremamente problemática hoje, como bem apontam autores como Hayden White (em sua Meta-História) e mesmo André Bazin (citado neste trabalho, sobre o cinema, a pintura e a fotografia). Mas a "febre" do realismo/naturalismo e sua visão um tanto cientificista eram a tônica do final do século XIX, sendo que o cinema e a fotografia eram vistos como "máquinas" de apreensão fidedigna do real (a fotografia, o instante; e o cinema, o movimento), em contraponto com a pintura (mais voltada para a "arte" e para a captura da "alma" do objeto representado, debate que aparece em "O Pintor de Retratos”), assim como a literatura também deveria se aproximar

\footnotetext{
${ }^{4}$ Embora extrapole os objetivos deste texto discutir em profundidade o conceito e as características do romance histórico, sugerimos esse debate como relevante para analisar as obras em questão. É nesse sentido que sugerimos como complemento (em especial para investigar a questão do uso de referências históricas) a leitura e estudo das "técnicas de autentificação do discurso" propostas por Maria Teresa de Freitas na obra citada na bibliografia deste trabalho. É leitura útil que pode servir de aprofundamento para trabalhos futuros sobre o tema deste artigo, em especial o uso de referências históricas na literatura.
} 
o máximo possível da realidade representada, sendo, pois, mais "História" e menos "ficção". Assis Brasil parece querer debater isso tudo, mas numa proposta mais tradicional, que, um tanto contraditoriamente, lembra o Realismo/naturalismo pelo excesso de referências e porque parece desejar criar uma sensação de realidade e "verdade" no leitor justamente pelo uso dessas referências.

Essa questão do excesso de referências também nos remete a Roland Barthes e seu "efeito de real", com seus "pormenores inúteis", sendo que o autor discute, exatamente sobre o realismo/naturalismo, qual seria a "significação dessa insignificância", gerando o que ele denomina "ilusão referencial":

\begin{abstract}
O barômetro de Flaubert, a pequena porta de Michelet afinal não dizem mais do que o seguinte: nós somos o real; [...] a própria carência do significado em proveito só do referente torna-se o significante mesmo do realismo: produz-se um efeito de real (Barthes, 1984, p. 160-164).
\end{abstract}

Fazendo um paralelo com o cinema, também podemos lembrar de Gilles Deleuze e seu regime de "imagem-tempo", em que os detalhes, os "vazios" e "excessos" do cotidiano se sobrepõem ao tempo diegético das narrativas convencionais do regime de "imagem-movimento".

No entanto, em "O Pintor de Retratos" o problema parece ser que a simples menção a nomes de locais, ruas, etc. não consegue criar no leitor essa identificação com o real que o próprio romance realista/naturalista conseguia, talvez pela linguagem um tanto enxuta do texto e pelo excesso de referências. Pensando na questão da "imagem-tempo" de Deleuze, em que o fluxo de consciência de um personagem, por exemplo, pode perfeitamente "preencher" os "vazios" do cotidiano, do "tempo puro" e não diegético (e há várias técnicas cinematográficas para criar esse efeito na narrativa), isso é algo que talvez pudesse ser feito na obra de Assis Brasil. Ou seja: o uso de técnicas literárias para retratar o fluxo de consciência de Sandro Lanari, por exemplo, entremeado com o uso de referências históricas, poderia, talvez, ser mais eficiente nessa aproximação do leitor com o "real". Mas essa não parece ser a proposta de Assis Brasil...

Outra questão é que em "A Margem Imóvel do Rio" nos parece que o autor evita o excesso de referências meramente nominais, o que confere um maior equilíbrio formal e temático, aproximando o leitor de uma representação mais convincente (talvez a palavra correta seja verossímil) do Rio Grande do Sul daquela época. Podemos dizer que, de certa maneira, Assis Brasil dá mais ênfase às personagens e seus conflitos individuais, deixando o contexto histórico propriamente dito num segundo plano, sem tantas referências diretas. Esse caminho que vai do individual ao social, da personagem ao contexto histórico em que atua, ou seja, de "dentro para fora" contribui, a nosso ver, para uma representação que melhor aproxima o leitor à época retratada. Já em "O Pintor de Retratos", embora a narrativa também tenha como centro as personagens, seu entrelaçar com o contexto histórico, feito muitas vezes através de referências diretas a nomes, locais, etc., soa artificial, na medida em que em diversos momentos o social se sobrepõe ao

\footnotetext{
${ }^{5}$ Aqui sugerimos tanto a leitura das obras originais de Gilles Deleuze sobre os conceitos de "imagemtempo" e "imagem- movimento" como também a leitura da obra comentada de Peter Pál Pelbart, seu tradutor no Brasil. Todas estão referenciadas no final deste trabalho.
} 
individual, as personagens se submetem a um contexto histórico construído de "fora para dentro", de maneira a parecer forçado e inverossímil.

Não se pode esquecer que a temática dos dois romances é exatamente a questão da representação da realidade. Essa é, sem dúvida alguma, uma das principais características que faz deles um "díptico", em que o olhar estrangeiro sobre o Rio Grande do Sul está intimamente ligado à busca de uma representação o mais "fiel" (mimética) possível da realidade ou à impossibilidade de isso se concretizar.

Em "O Pintor de Retratos" temos a história de Sandro Lanari, um italiano que acaba migrando para o Brasil, após um período de "peregrinação" pela Europa, e que chega a Porto Alegre, no final do século XIX, onde se estabelece e acaba atuando como pintor de retratos. Mais tarde, por uma série de circunstâncias de sua vida, vai para Rio Pardo e se envolve na Revolução Federalista. Em seguida, volta para a capital a passa a atuar como fotógrafo. No livro, a discussão sobre a representação da realidade se refere às possibilidades ou impossibilidades da arte em atingir a perfeição mimética, no caso, a fotografia e a pintura, debate que sem dúvida alguma era uma questão central no final do século XIX e que se acentua com o surgimento do cinema.

Para o pesquisador Ivo Canabarro, no século XIX a fotografia era vista como espelho do real, ou seja, como uma imitação mais do que perfeita da realidade, isso porque o que se pretendia era um discurso decorrente do caráter técnico da foto em contraposição à pintura, por exemplo, considerada como obra de arte $^{6}$.

Segundo Ana Maria Mauad, havia, para boa parte da intelectualidade da época, uma ênfase na:

[...] separação arte/fotografia, concedendo à primeira um lugar na imaginação criativa e na sensibilidade humana, própria à essência da alma, enquanto à segunda é reservado o papel de instrumento de uma memória documental da realidade, concebida em toda a sua amplitude (MAUAD, 1996, p. 76).

André Bazin, importante teórico do cinema, afirma sobre o tema:

[...] a pintura se esforçava, no fundo, em vão, por nos iludir, e esta ilusão bastava à arte, enquanto a fotografia e o cinema são descobertas que satisfazem definitivamente, por sua própria essência, a obsessão de realismo (BAZIN, 1983, p. 124).

O cinema, portanto, dando continuidade às tentativas humanas de apreensão do real, aparece como uma possibilidade de representação quase que integral da vida, principalmente devido à reprodução do movimento, algo que a fotografia não possibilitava. O filme, como diz Bazin (1983, p. 126), "não se contenta mais em conservar para nós o objeto lacrado no instante [...]. Pela primeira vez, a imagem das coisas é também a imagem da duração delas [...]". O problema é que até hoje o homem ainda não foi capaz de atingir seu objetivo de captação fiel da realidade, seja através da Arte, da

${ }^{6}$ CANABARro, Ivo. Possibilidades de Leitura do Real Pelas Imagens: A Fotografia Como Documento Histórico. Trabalho apresentado no "III Encontro Estadual de História", realizado na PUCRS, em Porto Alegre-RS, entre os dias 10 e 13 de setembro de 1996. 
Filosofia ou de qualquer outra área de conhecimento. Atualmente sabemos que todas essas tentativas não passam de representações de fragmentos isolados da realidade, que envolvem sempre questões problemáticas como a linguagem e a subjetividade, o que não nos permite uma apreensão fidedigna do real. Mas essa não era a mentalidade do século XIX, ávido em descobertas, quando ainda se acreditava nas possibilidades emancipatórias da razão e da técnica, próprias da modernidade.

É nesse sentido que Bazin ironiza aquilo que denomina "mito do cinema total", ressaltando a impossibilidade de imitação integral da natureza:

Os verdadeiros primitivos do cinema, aqueles que só existiram na imaginação de uns dez homens do século XIX, pensam na imitação integral da natureza. Logo, todos os aperfeiçoamentos acrescentados pelo cinema só podem, paradoxalmente, aproximá-los de suas origens. O cinema ainda não foi inventado! (BAZIN, 1991, p. 31).

O tumultuado relacionamento de Sandro Lanari com o fotógrafo Nadar e o episódio da "Foto do Destino", ocorrido durante a Revolução Federalista, são momentos em que fica explícita a problemática da arte enquanto representação. Essa discussão é ampliada mais ainda na medida em que o problema da representação passa a ser uma questão existencial para Sandro Lanari, sendo que sua própria vida é posta em conflito diante de tal embate. Os limites da arte são expostos de forma muito inteligente no final do livro, quando Assis Brasil admite que tanto a fotografia quanto a pintura (ou qualquer outra manifestação artística, mesmo o cinema) são capazes apenas de retratar fragmentos da realidade, e nunca a sua total complexidade: "É o retrato de um homem, mas é impossível formá-lo por inteiro. Faltam muitos pedaços, muitos... [...]” (p. 181). A própria citação de Montaigne, uma das epígrafes do livro, é uma pista da interpretação do autor acerca das possibilidades e limites da arte enquanto "mimésis": "Na verdade, o homem é de natureza pouco definida, extremamente desigual e variado. É difícil julgá-lo de maneira decidida e única".

Em “A Margem Imóvel do Rio" o problema da representação da realidade volta-se para a Literatura e as Ciências Humanas, especialmente a História e a Geografia. Também ambientado no final do século XIX, narra a história do cronista oficial da corte de D. Pedro II, o "Historiador", que viaja ao Rio Grande do Sul em busca de um tal Francisco da Silva a quem o imperador teria prometido um título nobiliárquico duas décadas antes. O "Historiador" sai do Rio de Janeiro, passa pela capital gaúcha e visita diversas regiões do interior de nosso Estado, quando discute internamente sua própria existência a partir da percepção dos limites de sua atividade como cronista. Ficam claros no livro os limites da História enquanto ciência, e os intensos processos de ficcionalização que ela sofre. A noção de "verdade" é questionada e até mesmo a representação fiel, objetiva e científica da realidade é posta em dúvida: "Os geógrafos [...] inventam o que não sabem, tal como os historiadores", diz o Historiador em uma passagem (p. 34). E o narrador do livro complementa: "Aliás, dada a mentira geral, nunca vira um Historiador concordar com outro" (p. 34). As dificuldades para encontrar o tal Francisco da Silva e as dúvidas inclusive sobre a sua real existência são um belo exemplo de como Assis Brasil "brinca" com os limites da História e da noção de "verdade". As ambigüidades e vazios que o autor 
deixa em aberto ao leitor na medida em que são apresentados os diferentes "suspeitos", ou seja, os vários "Franciscos da Silva", mostram com acidez as fragilidades da ciência histórica na sua missão de representar objetivamente a realidade. Sábias são as palavras do Historiador: "O pampa é único e perpétuo, e a memória é múltipla e frágill" (p. 72). E ferina é a ironia do narrador: "Historiadores não são dados a mentiras" (p. 24).

Outro aspecto que caracteriza a preocupação de Assis Brasil com a representação da realidade é o conflito "civilização x barbárie", presente em praticamente toda a sua obra, inclusive nos dois livros de que estamos tratando neste texto. O próprio Assis Brasil, em palestra realizada na $\mathrm{PUCRS}^{7}$, afirmou que este conflito é algo que o aflige internamente, o que sempre acaba sendo retratado em sua obra literária, como uma espécie de catarse do autor consigo mesmo e com esse sentimento. Uma das passagens de "O Pintor de Retratos" em que a realidade é apresentada de forma mais artificial é justificada por Assis Brasil ${ }^{8}$ como um "momento de raiva" em que o autor não conseguiu se conter diante da contradição entre civilização e barbárie. É um trecho em que Assis Brasil fala das revoluções que assolaram o Rio Grande do Sul no decorrer da sua História e descreve em detalhes a prática da degola. Em seguida, o autor promove um corte brusco no texto para informar o leitor de que enquanto em nosso Estado ocorria esta "barbárie", em Paris "Rodin esculpia Le baiser em mármore finíssimo, e Debussy compunha o delicado L'Après midi d'un faune. Nadar consolidava-se como o maior fotógrafo do século, ao retratar Debussy e Rodin" (p. 121). O trecho soa muito artificial no livro devido à bruteza da mudança de assunto e das referências históricas apontadas pelo autor. No entanto, pensando-o a partir desta lógica de contraponto entre civilização e barbárie, pode realmente ser considerado como uma espécie de desabafo existencial de Assis Brasil.

Pensando no enredo e nas personagens dos livros, podemos dizer que Sandro Lanari e o "Historiador" também estão em permanente conflito interior, perambulando pelos diversos níveis de barbárie e civilização a que estão submetidos. A Europa e o Rio de Janeiro, respectivamente, para Sandro e o Historiador, representam a civilização. E o interessante é que para ambos o Rio Grande do Sul, especialmente o interior do Estado, é a barbárie. E esse conflito entre barbárie e civilização é também um conflito existencial, a partir do qual as personagens tentam encontrar um sentido para suas vidas, uma verdade que sustente a sua própria mimésis, enquanto atores que atuam no palco de uma realidade ao mesmo tempo bárbara e civilizada.

Tanto Sandro Lanari quanto o Historiador buscam um sentido existencial e uma representação perfeita, mimética, o mais realista possível, do mundo que os cerca. Um o faz através da arte (fotografia e pintura) e o outro busca seu intento pela ciência (a crônica histórica e seu desejo de "verdade"). Mas ambos, imersos no conflito entre barbárie e civilização, não alcançam resultados satisfatórios. Seus "instrumentos" são falhos. Não são capazes de atingir a perfeição. Representam a realidade de uma forma fragmentada, imperfeita, parcial. Tal como suas próprias vidas e a compreensão que possuem a respeito delas.

\footnotetext{
${ }^{7}$ No dia 07 de outubro de 2003, em curso sobre "História do Rio Grande do Sul" promovido pela PróReitoria de Extensão Universitária da PUCRS.

${ }^{8} \mathrm{Na}$ referida palestra.
} 
De igual modo, Luiz Antonio de Assis Brasil, ao escrever "O Pintor de Retratos" e "A Margem Imóvel do Rio", tentativas de representação da realidade através da Literatura, também não obtém resultados "perfeitos". Seu "instrumento" também é falho. Preso na "gaiola da linguagem", como diria Wittgenstein, Assis Brasil também não consegue escapar de si mesmo, de sua subjetividade, do embate entre civilização e barbárie que o assola e da interminável distância que separa o homem do mundo em que vive. A palavra também é imperfeita. Assis Brasil por vezes escorrega seu texto por caminhos tortuosos, deixando-se levar por uma tentativa de representação realista que acaba se tornando artificial porque excessiva em seus detalhes. Mas o que verdadeiramente importa é que, mesmo fragmentada, parcial, subjetiva, tanto quanto os retratos de Sandro Lanari e as crônicas do Historiador, a obra literária de Assis Brasil nos enche a vida de sentidos. Múltiplos sentidos, aliás. E pelo simples fato de proporcionar a reflexão sobre as possibilidades que tem o ser humano de representar os seus mundos e paixões, também plurais, é que pode ser chamada de "realista". Não o "realismo" totalizante e maniqueísta, que simplifica a complexidade do mundo. Mas o "realismo" do bom e velho Machado de Assis, ou seja, o "realismo" da multiplicidade, em que é perfeitamente possível e compreensível que "faltem pedaços" do retrato de um homem ou que existam "Franciscos da Silva" em abundância perdidos nos cantões mais distantes da imensidão do pampa.

\section{REFERÊNCIAS}

ASSIS BRASIL, Luiz Antonio de. A margem imóvel do rio. Porto Alegre: L\&PM, 2004.

O pintor de retratos. Porto Alegre: L\&PM, 2001.

ASSIS, Machado de. Eça de Queirós: O Primo Basílio. In: Obra Completa, v. 3. Rio de Janeiro: José Aguilar, 1962, p. 903-913.

Notícia da atual literatura brasileira: instinto de nacionalidade. In: Obra Completa, v. 3. Rio de Janeiro: José Aguilar, 1962, p. 803-815.

BARTHES, Roland. O efeito de real. In: o Rumor da Língua. São Paulo: Brasiliense, 1984.

BAZIN, André. O cinema - ensaios. São Paulo: Brasiliense, 1991.

Ontologia da imagem fotográfica. In: XAVIER, Ismail (Org.). A experiência do cinema. Rio de Janeiro: Graal/Embrafilme, 1983.

CANABARRO, Ivo. Possibilidades de leitura do real pelas imagens: a fotografia como documento histórico. Trabalho apresentado no "III Encontro Estadual de História", realizado na PUCRS, em Porto Alegre-RS, entre os dias 10 e 13 de setembro de 1996.

DELEUZE, Gilles. Imagem-tempo. São Paulo: Brasiliense, 2005.

FREITAS, Maria Teresa de. Literatura e história. São Paulo: Atual, 1986.

MACHADO, Arlindo. Pré-Cinemas e pós-cinemas. Campinas: Papirus, 1997.

MAUAD, Ana Maria. Através da imagem: fotografia e história - Interfaces. In: Revista "Tempo". Rio de Janeiro: vol. 1, 1996, p. 75-88.

PELBART, Peter-Pál. O tempo não-reconciliado: imagens do tempo em Deleuze. São Paulo:

Perspectiva, 1998.

SENNA, Marta de. Machado de Assis: "certo instinto de nacionalidade". In: Escritos. Revista do Centro de Pesquisa da Casa de Rui Barbosa, Rio de Janeiro: Edições Casa de Rui Barbosa, ano 3, n. 3 , 2009, p. 77-90.

WHITE, Hayden. Meta-história: a imaginação histórica do século XIX. Trad. José. L. De Melo. 2 ed. São Paulo: Edusp, 1995. 
Recebido em 22/04/2016. Aprovado em 05/06/2016.

Title: The representation of reality in "O Pintor de Retratos" and "A Margem Imóvel do Rio", Luiz Antonio de Assis Brazil.

Abstract: The objective of this study is to analyze two books of the writer Luiz Antonio de Assis Brazil whose main objective is to discuss the representation of reality in different languages. "O Pintor de Retratos" (2001) deals with the debate between photography and painting as funding instruments "objective" reality, from a plot that takes place in the late nineteenth century. In "A Margem Imóvel do Rio" (2004) the reality of the representation of the problem back to the Literature and History. Also set in the late nineteenth century, tells the story of the official chronicler of the court of Dom Pedro II, who travels to Rio Grande do Sul in search of Francisco da Silva, whom the emperor had promised a title of nobility. In addition to the themes of each book, the idea of this study is also discuss their own literary works of the author as producers of meaning(s) for the construction of a certain view on the representation of realities addressed.

Keywords: Literature. Representation. Reality.

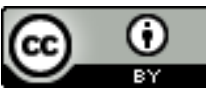

Este texto está licenciado com uma Licença Creative Commons Atribuição 4.0 Internacional. 